\title{
Paris Agreement CCS Policy and Mechanisms
}




\section{About KAPSARC}

The King Abdullah Petroleum Studies and Research Center (KAPSARC) is a non-profit global institution dedicated to independent research into energy economics, policy, technology and the environment, across all types of energy. KAPSARC's mandate is to advance the understanding of energy challenges and opportunities facing the world today and tomorrow, through unbiased, independent, and high-caliber research for the benefit of society. KAPSARC is located in Riyadh, Saudi Arabia.

\section{Legal Notice}

(c) Copyright 2019 King Abdullah Petroleum Studies and Research Center (KAPSARC). No portion of this document may be reproduced or utilized without the proper attribution to KAPSARC. 


\section{Key Points}

arbon capture and storage (CCS) is one of a limited number of ways to reach the Paris Agreement's objective of net-zero carbon dioxide $\left(\mathrm{CO}_{2}\right)$ emissions in the second half of this century. The world's remaining carbon budget of 900 gigatonnes (Gt) will become depleted around 2040 at the current emissions rate of some 40 Gt per year. Deploying CCS at scale provides an economically feasible way of achieving the net-zero objective.

A recent KAPSARC publication, "A Mechanism for CCS in the Post-Paris Era," developed the concept of a new CCS-specific technology mechanism under Article 6 of the Agreement that could overcome historical barriers to the deployment of CCS. This would take the form of a new tradable asset or carbon storage unit (CSU) representing one verified tonne of $\mathrm{CO}_{2}$ stored or sequestered geologically with no intrinsic emissions reduction value.

The CSU approach reframes the climate challenge as one of managing carbon stocks as opposed to annualized carbon emissions flows. It thereby emphasizes climate action on the supply side.

A CSU would represent a non-greenhouse gas metric under the Paris Agreement. It would be tradable as an internationally transferred mitigation outcome under Article 6.

Fossil fuels, such as crude oil, could be linked or 'tagged' to CSUs that would essentially establish a decarbonized fossil fuel product and help contribute to net-zero emissions.

Demand for CSUs could be incorporated into existing mechanisms and policies that aim to decarbonize oil. The implementation could be pilot-based, transitional and gradually scaled up.

The ongoing Article 6 negotiations could play a facilitative role in CSU implementation by including multiple metrics based on countries' national preferences, reflecting the Agreement's bottom-up spirit of cooperation.

Figure 1. A possible virtuous circle for a dedicated CCS support mechanism.

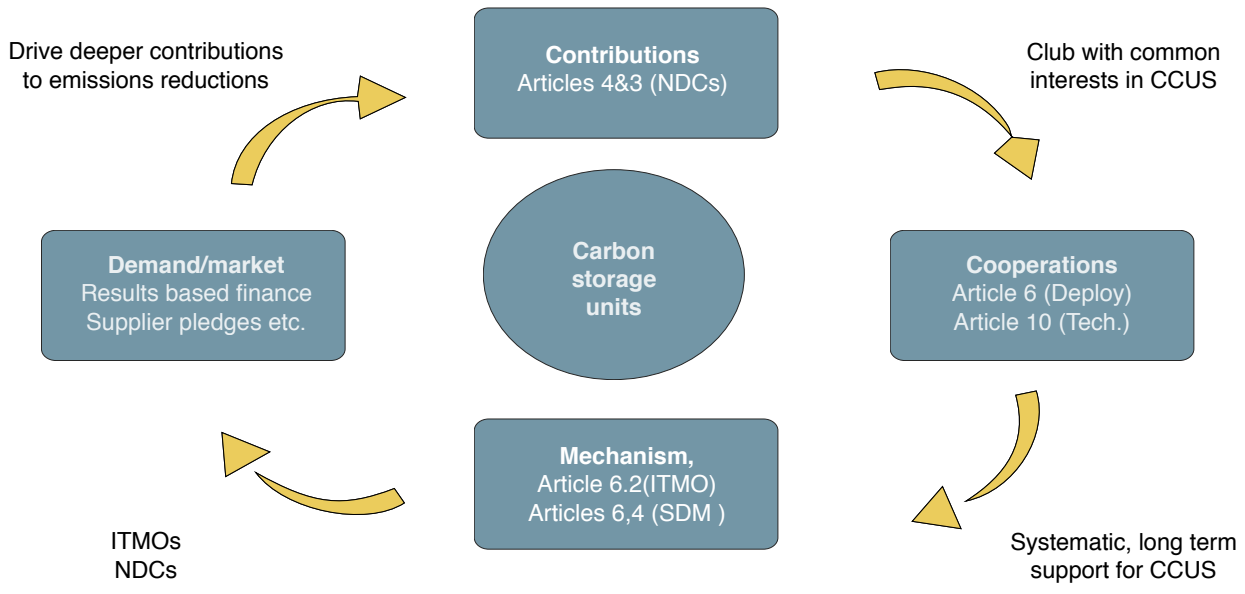

Key: CCUS = Carbon capture utilization and storage; CSU = Carbon storage unit; ITMO = Internationally transferred mitigation outcome; NDCs = Nationally determined contributions; SDM = Sustainable development mechanism.

Source: KAPSARC. 


\section{Summary}

$\mathbf{T}$ The Paris Agreement commits its 195 signatory Parties to achieve a balance between anthropogenic emissions by sources and removals by sinks in the second half of this century, or net-zero emissions.

Achieving net-zero emissions by the end of the century translates into a remaining 'carbon budget' of some 900 gigatonnes of carbon dioxide $\left(\mathrm{GtCO}_{2}\right)$. In comparison, the remaining geosphere carbon stock stands at over $11,000 \mathrm{GtCO}_{2}$ in the form of, among other things, fossil fuels. At current emission rates of some $40 \mathrm{Gt}$ per year, this 'carbon budget' will be depleted by around 2040, after which date net-zero emissions will be required to keep the Earth's temperature increase to within 2-degrees Celsius (C) of pre-industrialization levels, a key target of the Paris Agreement.

Carbon capture and storage (CCS) has a critical role to play in reaching net-zero emissions by 2040 . Its deployment at scale has, until now, been impeded by a lack of adequate commercial and regulatory incentives. Ongoing negotiations on Article 6 provide a window of opportunity to design new rules to incentivize the deployment of CCS based on an alternative, stock-based view of the climate challenge.

A recent KAPSARC publication, "A Mechanism for CCS in the Post-Paris Era," argues that a new CCS-specific technology mechanism could be set up under Article 6, backed by a group of countries (or 'club'), with a common interest in pursuing cleaner fossil fuels. This mechanism would promote a new tradable asset specific to CCS: a carbon storage unit (CSU) that would represent one verified tonne of $\mathrm{CO}_{2}$ stored or sequestered geologically. It would have no intrinsic emissions reduction value.
A CSU would function under Article 6 of the Paris Agreement as a non-greenhouse gas (GHG) metric that would be tradable as an internationally transferred mitigation outcome. Storage crediting essentially reframes the climate challenge as one of carbon stock management rather than one of annualized $\mathrm{CO}_{2}$ emissions flows. It thereby shifts the emphasis for action toward the supply-side rather than the demand (user) side.

Linking or 'tagging' fossil fuels such as crude oil to carbon storage credits could create offsetting opportunities and establish decarbonized fossil fuel products. CSUs could thus help deliver both cleaner fossil fuel products and net-zero emissions. Existing policies and mechanisms that could accommodate storage units include the Carbon Offsetting and Reduction Scheme for International Aviation, California's Low Carbon Fuel Standard and the European Union's Renewable Energy Directive.

The implementation of the CSU scheme could be a pilot-based, transitional approach that could combine emissions and stock-based regulations. This would help resolve the initial questions of where demand for storage credits may be. A key challenge is the need to move beyond the current focus of most climate policies on emissions, in favor of introducing a supply-side, carbon stocks approach. The current Article 6 negotiations can play a facilitative role in promoting CSUs by including several metrics relevant to respective national priorities, in line with the bottom-up, country-driven and cooperative spirit of the Paris Agreement. 


\section{Background to the Workshop}

APSARC hosted the workshop in Riyadh, Saudi Arabia, on Apr. 9 and 10, 2019.

The event brought together a wide range of international experts and stakeholders from government, industry and academia who focus on the topic of carbon capture and geological storage (CCS) in the post-Paris Agreement era. The context for the workshop was a recent KAPSARC discussion paper, "A Mechanism for CCS in the Post-Paris Era: Piloting Results-Based Finance and Supply-Side Policy Under Article 6" (https://www. kapsarc.org/research/publications/a-mechanism-forccs-in-the-post-paris-era/).

The paper proposed the establishment of a transformative, incentive mechanism for CCS under Article 6 of the Paris Agreement, forged by a 'club' of Parties with a common interest: the pursuit of cleaner fossil fuels. The CCS-specific technology mechanism and club would be built upon a new tradable asset class specific to CCS: a carbon storage unit (CSU). A CSU would represent a verified tonne of carbon $(\mathrm{tC})$ or a tonne of carbon dioxide ( $\mathrm{tCO} 2$ ) securely stored or sequestered in a geological reservoir, i.e., a verified record of carbon stock addition to the geosphere, but with no intrinsic emissions reduction value.
The paper argues that such a storage crediting scheme could complement and supplement carbon pricing, unlock new layers of climate finance for CCS, and overcome some of the barriers that the technology has historically faced. The proposal and workshop are timely because the rules regarding the operation of Article 6 mechanisms under the Paris Agreement are presently under discussion and could conclude later in 2019.

The purpose of the two-day workshop was to:

Explore the status of CCS under the Paris Agreement with experts and key stakeholders.

Gather feedback on the proposal outlined in KAPSARC's recent discussion paper on the topic.

Establish an informal network that could support actions to develop CCS policies within the United Nations Framework Convention on Climate Change (UNFCCC). 


\section{Workshop Sessions}

The workshop sessions focused on three core elements that lie at the center of the UNFCCC's CCS policy.

\section{The Paris Agreement and Article 6}

The first session discussed the origins, status and current development of the Paris Agreement.

Presenters reminded participants that the goal of the Agreement is to limit the global mean average temperature increase to within 2-degrees Celsius (C) of pre-industrialization levels and to pursue efforts to limit the increase to $1.5 \mathrm{C}$. Ultimately, Article 4 of the Agreement requires all Parties to achieve a balance between anthropogenic greenhouse gas (GHG) emissions by sources and removals by sinks in the second half of this century (often referred to as netzero emissions).

It was noted that all Parties to the Paris Agreement are expected to contribute toward its ultimate goals, and in doing so, they must make ambitious pledges for climate action in the form of nationally determined contributions (NDCs) every five years from 2020 onwards. Parties' subsequent NDCs must represent a progression beyond their previous ones.

The rules for Article 6 mechanisms - schemes through which Parties may cooperate to achieve or exceed NDC ambitions - were not agreed at the U.N.s Katowice Climate Conference in 2018 (COP24). Thus, Article 6 rules remain subject to ongoing uncertainty. Participants discussed areas of convergence and divergence between Parties. Many of the current negotiating challenges relate to how units should be accounted for when transferred between cooperating Parties. Further work on Article 6 rules will be undertaken at the UNFCCC Subsidiary Body meeting in June 2019 (SB50), with a view to finalizing and agreeing them at the U.N.s Santiago Climate Conference scheduled for December 2019 in Santiago, Chile (COP25). The possibility for finer points to be carried over for future negotiations, and/or of no rules being agreed at all, were also highlighted as potential outcomes.

The workshop also addressed the topics of 'nonGHG' metrics in NDCs and transferable units ('ITMOs') under Article 6. Many Parties to the Paris Agreement have pledged climate mitigation contributions in their NDCs that are not explicitly measured as emissions reductions but in other metrics that can result in GHG emissions reductions or sink enhancements as co-benefits. Examples of these contributions include megawatts of renewable energy and areas of newly forested land. Other types of metrics to measure and transfer climate action are still subject to negotiations among Parties, and uncertainties persist over whether such units could be traded as part of Article 6 mechanisms.

\section{Carbon budgets, stocks, storage credits and net-zero decarbonization}

The second session reviewed the scientific basis for restricting GHG additions to the Earth's atmosphere, an objective consistent with meeting the Paris Agreement goals.

Experts highlighted that limiting global temperatures to $2{ }^{\circ} \mathrm{C}$ above pre-industrial levels leaves an approximate atmospheric 'carbon budget' of 900 gigatonnes of carbon dioxide $\left(\mathrm{GtCO}_{2}\right)$. Meanwhile, there is a remaining geosphere carbon stock of over $11,000 \mathrm{GtCO}_{2}$ in the form of, inter alia, fossil fuels. The $2{ }^{\circ} \mathrm{C}$ atmospheric carbon budget will be depleted by around 2040 at current emission rates (around $40 \mathrm{GtCO}_{2}$ per year). Thereafter, it will be necessary to maintain net-zero emissions to keep the Earth's temperature increase to within $2^{\circ} \mathrm{C}$ above pre-industrial levels by 2100 . It was noted that this situation poses a threat to the value of fossil fuel resource endowments without the use of CCS. It was also noted that delaying action now increases 
the rate at which action in the future will be needed, which would add to the future cost of climate change mitigation.

It is useful to frame the climate change mitigation challenge as one of stock management (such as managing inventories of carbon stocks in the geosphere, atmosphere and biosphere) as much as it is of emissions management, i.e., reducing annualized $\mathrm{CO}_{2}$ flows to the atmosphere. Taking a stock-based view offers a different perspective on methods to solve the problem and links with the area of policy design that aims to achieve and sustain a balance between GHG emissions, additions to and removals from the atmosphere.

The concept of linking oil production (i.e., carbon stock extraction from the geosphere) with the remaining atmospheric carbon budget was outlined. Over time, an increasing fraction of the mass of carbon extracted from the geosphere (production) could be offset by increasing amounts of geologic carbon sequestration. Ultimately, a net-zero emissions outcome is possible when carbon extraction is entirely balanced by carbon sequestration, i.e., it is $100 \%$ offset. The fraction of carbon extracted from the atmosphere offset at any given time would be determined by the depletion rate of the remaining atmospheric carbon budget. In practice, the storage crediting approach would involve tagging produced fossil fuels (e.g., crude oil) with storage credits equivalent to a portion, or all, of the carbon or $\mathrm{CO}_{2}$ embodied within the produced fuel. This would be the most practical way of implementing the offset approach described: essentially establishing a 'decarbonized' fossil fuel product.

To highlight the possibilities of this approach, an industrial scenario for achieving net-zero emissions and decarbonization of fossil fuels was presented based on Shell's 'Sky' scenario. The Sky scenario outlines a pathway for future energy development consistent with the Paris Agreement's net-zero emissions goal. It assumes a hypothetical situation where, in 2070, $16.5 \mathrm{GtCO}_{2}$ is produced from the geosphere, $9.5 \mathrm{GtCO}_{2}$ is added back through CCS, and the balance is managed through biomass and other nature-based solutions. The Sky scenario also assumes carbon cycling in 2100 .

Given all of the above, it was argued that measuring CCS activities as stock additions through storage credits instead of as emissions reductions (i.e., as an avoided emissions credit) has merits. The advantage is principally from allowing the production of carbon from reservoirs providing that it is offset by the geosequestration of carbon back into reservoirs. It was noted that this approach also shifts the emphasis of climate action toward the supply side rather than the demand (user) side and thereby offers a way toward establishing decarbonized fossil fuel products.

The proposal for operationalizing a storage crediting system under Article 6 of the Paris Agreement, articulated in the recent KAPSARC discussion paper, was presented. It outlines a potential transitional, pilot, approach to storage crediting, using stock-based, supply-side, policies that can complement and supplement existing emissionsbased climate policies.

\section{Exploring polices and measures that could accommodate storage credits}

The third session of the workshop reviewed existing policies and measures that may be able to provide a mechanism by which to create systematic demand for storage credits.

Presenters outlined the current rules in place or under development for schemes focused on reducing emissions from liquid fuels. These covered the Carbon Offsetting and Reduction Scheme 
for International Aviation (CORSIA), the United States (U.S.) California Low Carbon Fuel Standard (C-LCFS), and the European Union (EU) Renewable Energy Directive (RED) and Fuel Quality Directive (FQD).

The International Civil Aviation Organization is considering introducing rules for low carbon aviation fuels into CORSIA, which could include fuels derived from crude oil tagged with a storage credit, indicating that the supplier has offset its embodied carbon emissions. However, these rules have yet to be finalized.

The C-LCFS imposes a system for reducing the GHG intensity of liquid fuels used in the U.S. state of California. New rules for CCS under the C-LCFS place the emphasis only on reducing direct $\mathrm{CO}_{2}$ emissions arising across the fuel supply chain, rather than considering embodied carbon emissions in the fuel. As it stands, it would be difficult to incorporate the concept of decarbonized fuels in the C-LCFS using storage credits as described without modification.

The EU's FQD seeks to implement a similar policy to that of the C-LCFS, albeit with slightly different rules. The FQD failed to fully materialize, however, and the EU reviewed its approach to managing liquid fuels under its revised Renewable Energy Directive (RED II). RED II was approved by the European Parliament and the European Council in late 2018. However, it will probably need to be modified in order for the storage credit concept to be incorporated. 


\section{Discussion}

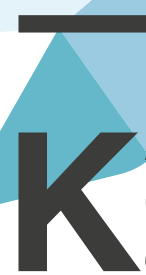

APSARC's recent discussion paper on CCS highlighted three uncertainties or implementing a storage crediting approach under the Paris Agreement. These are:

Compatibility with the Paris Agreement.

Broader acceptance.

Willingness to participate.

These three challenges provide a useful backdrop for framing the workshop outcomes.

\section{Compatibility with the Paris Agreement}

Some workshop participants advised caution with the approach outlined in KAPSARC's CCS discussion paper. They noted that it might be challenging for negotiators responsible for Article 6 to consider more types of units and mechanisms in what is an already complicated and challenging area for international climate policy negotiations.

Conversely, other participants noted that Article 6 should play a facilitative role: allowing different metrics to be applied that are relevant to national priorities and allowing cooperative climate action to occur between Parties united by common interests. Such cooperation, some argued, is a key feature of the bottom-up, country-driven spirit and ethos of the Paris Agreement.

\section{Broader acceptance}

As noted in the discussion paper, there is a deeprooted attachment to measuring climate action in emissions reductions (flows) rather than focusing on managing carbon inventories in different global pools (stocks). Reframing the challenge as a stock problem and carbon budget challenge can be useful when aiming for net-zero emissions. Several participants suggested that a shift in emphasis may not be particularly necessary since regulating emissions can achieve the same zero-emissions outcome.

However, others argued that emissions policies and pricing has not led to the deployment of CCS to date, and a subtle shift of emphasis toward policies also covering carbon stock could move part of the challenge upstream into supply-side policies and measures. With this in mind, participants considered how or why there may be demand for storage credits, given that the current focus of most climate policies is on emissions rather than on stocks. Many participants sought to find the ultimate 'end-game' solution to drive systematic demand for storage credits, rather than considering a phased and transitional approach that could be scaled-up over time.

Several participants noted that the KAPSARC CCS discussion paper proposes an approach that allows both emissions and stock-based regulation to co-exist for some time. After a piloting phase, the experiences gained would be reviewed and conclusions drawn on whether and/or how the approach could be either systematically integrated or dissolved. Dissolving it would involve reverting to the sole use of emissions-based policies and measures to drive the technology if the experiences of the approach proved negative.

\section{Willingness to participate}

In general, many participants were supportive of the proposed storage crediting, and none expressed outright opposition to the idea.

Some participants suggested linking the idea with NDCs because this could drive demand for storage credits. It was also noted that it might be useful to emphasize the long term 'pathways' aspects of the approach and to show how it can complement near-term climate action. 


\section{Conclusions}

road conclusions and actions from the workshop include:

Further articulation and communication of the concepts discussed. This will be necessary in order for stakeholders to understand and appreciate the potential benefits of storage crediting, and its associated nuances.

Further work may also be needed to demonstrate how the approach could function alongside current emissions-based policies and measures, and not lead to the double counting of reductions or removals. A regional pilot phase was suggested as a possible option.

Recommending that current negotiations on Article 6 rules under the Paris Agreement leave open the possibility for the further development of the storage crediting concept.
Possible platforms through which to further gauge opinion and communicate the proposal were identified as:

The Oil and Gas Climate Initiative (OGCl), including its current regionally-driven work programs such as the Gulf Region CCUS White Paper.

The Clean Energy Ministerial (CEM) and its planned meeting in May 2019.

Publication in academic journals.

Climate conferences (e.g., SB50, COP25). 


\section{About the Workshop}

his workshop is part of a project that examines policy options and analyzes related regulatory and commercial issues affecting the development and deployment of CCUS. It adopted a modified version of the Chatham House rule under which participants consented to be listed below, having joined on one or both days. However, none of the content of this briefing can be attributed to any individual attendee.

\section{List of participants}

Kimon Alexandrou - Saudi Aramco

Abdulrahmen Al-Gwaiz - Ministry of Energy, Industry and Mineral Resources (MEIM)

Aaesha Alkeebali - Abu Dhabi National Oil Company (ADNOC)

Myles Allen - University of Oxford

Hamoud Al-Otaibi - Ministry of Energy, Industry and Mineral Resources (MEIM)

Perumal Arumugam - UNFCCC Secretariat

Stuart Haszeldine - University of Edinburgh

Torleif Haugland - Carbon Limits

Gardner Hill - BP

David Hone - Shell
Takashi Hongo - Mitsui Global Strategic Studies Institute

Andrew Howard - Koru Climate

Zaour Israfilof - SABIC

Mohammed Juaied - Saudi Aramco

Juho Lipponen - Clean Energy Ministerial CCUS Initiative

David Livingston - Atlantic Council

Andrei Marcu - International Centre for Trade and Sustainable Development (ICTSD)

Tidjani Niass - Saudi Aramco

Laze Pejoski - G20 Saudi Secretariat

Grzegorz Peszko - World Bank

Andrew Prag - International Energy Agency (IEA)

Xiaoliang YangWorld Resources Institute - China Office

Sonia Yeh - Chalmers University of Technology

Paul Zakkour - KAPSARC /Carbon Counts

Wolfgang Heidug - KAPSARC

Elizabeth Carey - KAPSARC

Faris Al-Otaibi - KAPSARC 


\section{Notes}

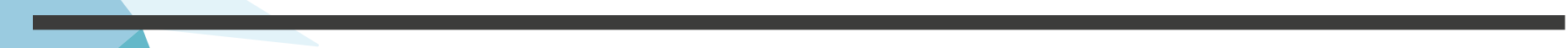


Notes

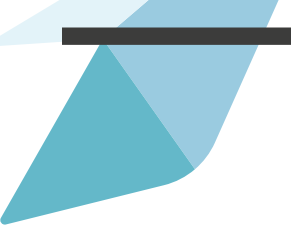




\section{Notes}

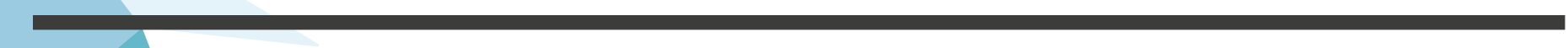




\section{About the team}

\section{Paul Zakkour}

Paul Zakkour is a director of consultancy Carbon Counts and a visiting researcher at KAPSARC. He has more than 17 years' experience in the fields of climate change policy, regulation and economics. Paul also has extensive expertise in CCS, having helped design European regulations in 2007 and 2008 and the United Nation's rules for the clean development mechanism in 2010 and 2011. Paul holds a Ph.D. in Environmental Technology from Imperial College, London.

\section{Wolfgang Heidug}

Wolfgang Heidug is a Senior Research Fellow in Climate and Environment at KAPSARC. He is an expert in low-carbon energy technology policy with an in-depth knowledge of the science and technology of CO2 capture and storage. Prior to joining KAPSARC, he was a senior adviser at the International Energy Agency (IEA) in Paris. Wolfgang has more than 20 years' experience working with Shell. He holds a Ph.D. in Engineering from Brown University in the United States (U.S), an M.Sc. in Physics from Berlin Technical University and a degree in Economics from Hagen University, Germany.

\section{Elizabeth Carey}

Elizabeth is a Senior Research Associate, in Climate and Environment at KAPSARC. Prior to joining KAPSARC she was an energy advisor in the New Zealand delegation to the IEA/OECD and an energy policy analyst with a French think tank in Paris. She holds a doctorate in Political Science and International Relations from Paris II Pantheon-Assas University, and an MSc. in Political Science from the Massachusetts Institute of Technology in the U.S.

\section{About the Project}

This workshop is part of a project examining opportunities for Saudi Arabia to apply carbon capture, utilization and storage (CCUS) technologies in an increasingly carbon-constrained world, and investigating the role that CCUS could play in the Saudi economy. The project assesses policy options and analyzes related regulatory and commercial issues affecting the development and deployment of CCUS. 
INAPSARC

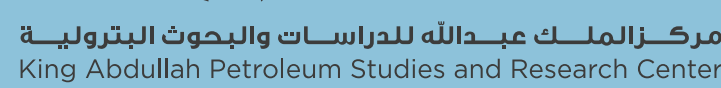

www.kapsarc.org 